\title{
Stress dynamics in long-term isolation at sea. A demographic variables model
}

\author{
${\text { Mieczysław } \text { Plopa }^{1}(\text {, Ryszard Makarowski }}^{2} \oplus$, Wojciech Plopa $^{3} \oplus$ \\ ${ }^{1}$ Institute of Psychology, University of Economics and Human Sciences, Warsaw, Poland \\ ${ }^{2}$ Department of Administration and Social Sciences, Elblag University of Humanities and Economy, Elblag, Poland \\ ${ }^{3}$ University of Economics and Human Sciences, Warsaw, Poland
}

\begin{abstract}
The current article describes a naturalistic research programme carried out among fishermen during a 6-month expedition to the southern Atlantic Ocean. Stress levels of 81 participants were measured 4 times during the expedition. Social-demographic variables (age, years of experience at sea, job satisfaction, education, current and childhood place of residence, relationship status) were also included in the analysis. Results show that these variables should be considered when analysing stress dynamics among people experiencing long-term work-related isolation.
\end{abstract}

(Int Marit Health 2020; 71, 2: 140-146)

Key words: sea isolation, demographic variables, stress, anxiety, longitudinal study

\section{INTRODUCTION}

Research on stress and its effects on individual well-being, health, and functioning has seen a substantial increase in the last two decades. Theoretical models and empirical analyses both point to significant connections between quality of life and prevalence of diseases/mortality caused by stress.

The nature of maritime work causes chronic separation between the sailor and their family. Thus, such families experience characteristic cycles of the sailor (parent, spouse) leaving and returning. The stress thus generated necessitates the use of various coping mechanisms. Practical observation suggests that, despite protests on this point, institutions employing fishermen do not seem to pay particular attention to the psychological and health costs they and their families incur. Short periods of rest at home can allow the fishermen to "regenerate" their psychological resources, but they can also inhibit or make virtually impossible the "reactivation" of basic marriage and family roles. Through the delegation of responsibility on their wives, lack of knowledge of common and specific problems of family life, and marginal input in family decision-making, sailor husbands can experience difficulties in self-acceptance in the family context. Consequently, they can cope by "escaping back to sea."
The second significant factor in the development and maintenance of stress among fishermen and their families are the conditions at sea. The ship creates a specific work environment characterised by a closed, paramilitary structure of leadership and spatial confinement. Significant stressors also include the ship's movements, noise and vibration, frequent crossing of climate zones [1], temperature and air pressure fluctuations, for example, during storms [2], living space constraints, lack of typical emotional [3], sexual, and psychological gratification, lack of intimacy, separation from family [4, 5], loneliness, exhaustion, work in a multicultural crew [6], limited opportunities for recreation, and lack of sleep [7, 8]. The constant character of these stressors causes constant emotional tension in the majority of the fishermen. In turn, this tension increases with the duration of the expedition. Long-term stress ultimately contributes to increased mortality due to accidents, cancer, cardiovascular diseases, and suicide [9, 10].

Thus, the question arises of the psychological costs incurred by fishermen. These can be considered in the short- and long-term (repeated periods of isolation) perspective. Importantly, existing research has considered these psychological costs only to a minimal extent, focusing instead on difficulties in adaptation and work performance.

Prof. Mieczysław Plopa, Institute of Psychology, University of Economics and Human Sciences, ul. Pawia 55, 01-030 Warszawa, Poland, e-mail: plopa@vizja.pl 
In other words, the question concerned the individual, social, or organisational factors facilitating this adaptation or performance, rather than the accompanying costs. It is possible that a sailor can perform their work role well (e.g., in their supervisor's judgement), but at the cost of significant stress (i.e., negative emotional experiences, which are not taken into consideration by the supervisor). Prior studies have seldom, if at all, explored this issue from the individual differences perspective.

A review of the literature on stress shows that it is a virtually universal, complex phenomenon, determined by a variety of factors. Its duration and intensity mainly depend on an interaction of such factors as life experience (an individual's developmental course), individual differences, or sociocultural environment. Emphasis is placed on the necessity of a holistic approach both in methodology and data interpretation. The individual's experience and their environment influence one another - one family member's stress (e.g., an illness or marital conflict) indirectly affects the other members, both within and outside their family roles.

Thus, it seems pertinent to adopt a general assumption that an individual possessing appropriate levels of personal and social competences (chiefly within the family context) will function relatively effectively (without major stress) both in everyday life situations and difficult work conditions. Health psychology research seems to confirm this assumption by studying the psychological and social factors in numerous illnesses (including cancer), understood as the distal effects of stress. These are exacerbated by proximal stressors, varying between individuals. Fishermen, in particular deep-sea fishermen, are exposed to work-related stress and isolation. The risk of death in naval transportation is 3 times higher than in bus transportation. Compared to planes and trains, the risk of death on board a ship is 10 times as high. The human factor is responsible for nearly $80 \%$ of these incidents [11]. Exhaustion of the watch officers, steering errors, task overload, or a misplaced sense of safety caused by an over-reliance on automated systems result in an increased number of accidents. Thus, ship navigators' psychological functioning is especially important in the context of the errors they are liable to.

The current study thus attempts to answer the following questions: What causes the experience of stress to intensify during periods at sea for some fishermen, but not for others? What psychological factors lie behind these differences?

Of interest here is also the hypothesis, put forward on the basis of qualitative data (e.g., diaries), that as the duration of isolation (often involuntary isolation as well) increases, so does the role of demographic factors in coping with stress.

In sum, the current study focuses on demographic factors (independent variable) determining the dynamics of stress experience (dependent variable) among fishermen in conditions of long-term isolation at sea. The research question is as follows: Are particular demographic variables (age, education, relationship status, work experience, social-economic status, place of residence in childhood [cities vs. small towns], crew position, level of work satisfaction) related to differences between fishermen in stress experience during isolation at sea?

\section{METHODS}

Thus, researching it in terms of its dynamics requires integrating a range of variables, especially more so in the case of people undergoing prolonged social and emotional isolation. In the current study, state anxiety was measured with the state subscale of the State-Trait Anxiety Inventory [12]. This allowed for measuring changes in an individual's anxiety state as a consequence of environmental influences. Demographic data on the study group was collected using a structured survey (age, education, relationship status, number of expeditions, childhood residence, crew position, job satisfaction).

Cluster analysis of multiple state anxiety measurements has allowed distinguishing groups of fishermen on the basis of their dynamics of anxiety experience in various stages of long-term isolation at sea.

\section{SAMPLE}

The participants were between 21 and 53 years of age. Those from working class families constituted the largest group (76.5\%). The majority of the sample grew up in large (29.6\%) cities. $12.3 \%$ of the sample was on a deep-sea expedition for the first time in their career. The largest group had a vocational education (34.1\%). Only $11 \%$ of the crew was educated specifically as fishermen. The majority of the fishermen in the sample were married (87.7\%). $40.8 \%$ of the fishermen' families had 2 children (Table 1).

\section{PROCEDURE}

Participation in the study was voluntary. The fishermen were informed about the presence of a psychologist on board only after having arrived in Montevideo. The psychologist was obliged to prove their credibility and attest to strictly scientific purposes behind their presence. The aim of the study was presented to the crew during a meeting at the beginning of the expedition. The pragmatic aspect of the study was highlighted, that is, the possibility to use the results to improve expedition planning and to argue for a greater consideration of the fishermen' psychological needs by the management. The crew was assured of the anonymous character of the study and of the nondisclosure of individual results to the management. However, absolute anonymity of the research (i.e., the inability to match individual results to individual fishermen) was impossible due 
Table 1. Descriptive data for fishermen

\begin{tabular}{|c|c|c|}
\hline Variable & $\mathbf{N}$ & $\%$ \\
\hline \multicolumn{3}{|l|}{ Age [years] } \\
\hline Under 30 & 20 & 25.6 \\
\hline $31-40$ & 30 & 38.5 \\
\hline Over 41 & 28 & 35.9 \\
\hline Total & 78 & 100 \\
\hline \multicolumn{3}{|l|}{ Education } \\
\hline Primary school & 18 & 23.1 \\
\hline Vocational school & 27 & 34.6 \\
\hline High school & 26 & 33.3 \\
\hline College & 7 & 9.0 \\
\hline Total & 78 & 100 \\
\hline \multicolumn{3}{|l|}{ Relationship status } \\
\hline Single & 9 & 11.5 \\
\hline Married & 69 & 88.5 \\
\hline Total & 78 & 100 \\
\hline \multicolumn{3}{|l|}{ Number of expeditions } \\
\hline 1 & 9 & 11.6 \\
\hline $2-5$ & 17 & 21.8 \\
\hline $6-15$ & 27 & 34.6 \\
\hline 16 and more & 25 & 32.0 \\
\hline Total & 78 & 100 \\
\hline \multicolumn{3}{|l|}{ Childhood residence } \\
\hline Rural areas & 20 & 25.6 \\
\hline Small towns & 34 & 43.6 \\
\hline Large cities & 24 & 30.8 \\
\hline Total & 78 & 100 \\
\hline \multicolumn{3}{|l|}{ Crew position } \\
\hline Officer & 17 & 21.8 \\
\hline Regular crewmember & 61 & 78.2 \\
\hline Total & 78 & 100 \\
\hline \multicolumn{3}{|l|}{ Job satisfaction } \\
\hline Satisfied & 34 & 43.6 \\
\hline Not satisfied & 44 & 56.4 \\
\hline Total & 78 & 100 \\
\hline
\end{tabular}

to the continuous presence of the psychologist on board. Additionally, most of the fishermen were participating in psychological research for the first time, and thus, showed understandable apprehension towards revealing details of their psychological makeup and personal issues. A part of the sample withdrew their participation after a time, which might suggest that doubts about the purpose of the study were present all throughout its duration. For this reason, the help and motivation offered by the ship's captain and
Table 2. Fishermen' anxiety levels across and between expedition phases $(n=78)$

\begin{tabular}{lll}
\hline Expedition phase & M & SD \\
\hline I & 37.75 & 7.59 \\
II & 38.78 & 8.22 \\
III & 42.88 & 8.67 \\
IV & 37.89 & 8.23 \\
\hline Compared phases & $\mathbf{T}$ & $\mathbf{P}$ \\
\hline I-II & 0.80 & NS \\
I-III & 3.91 & 0.01 \\
I-IV & 0.10 & NS \\
II-III & 3.02 & 0.01 \\
II-IV & 0.68 & NS \\
III-IV & 3.67 & NS \\
NS - non significant; SD - standard deviation &
\end{tabular}

the doctor are to be acknowledged. The fishermen were also informed about the possibility of receiving their own individual results after the study's conclusion.

The schedule of data collection was established by the psychologist after becoming acquainted with the organisation of life on board, especially in the fisheries area, where work was particularly intensive. Stress (i.e., state anxiety) levels and its dynamics were measured four times throughout the expedition, on the $10^{\text {th }}, 60^{\text {th }}, 100^{\text {th }}$, and $130^{\text {th }}$ day. To respect the fishermen' time and freedom, they were personally given an envelope containing the questionnaires every 10-12 days. The psychologist explained the questionnaire instructions and answered any questions. The fishermen then had up to 2 days to complete the questionnaires. The psychologist only checked the questionnaires for full completion. Statistical analyses were carried out after the expedition.

\section{STRESS DYNAMICS}

Seventy-eight fishermen participated in four measures of state anxiety. The results are presented in Table 2 and in Figure 1. The highest levels of anxiety were exhibited during phase III (out of four) of the expedition, that is, after 100 days ( $M=42.88$ ). The lowest levels were recorded at the beginning $(M=37.75)$ and at the end ( $M=37.88)$. The differences between phase III and phases I, II, and IV were statistically significant.

Experienced anxiety varied over time. It increased as a function of the length of isolation and began to decrease towards the initial levels once the $2 / 3$ point of duration was passed. These results partially confirm the results of previous studies.

Results of a cluster analysis have confirmed the hypothesis. Two groups of fishermen were distinguished based on 
the differences in their reports of state anxiety throughout the subsequent phases of isolation. Figure 2 and Table 3 shows the profiles of these groups.

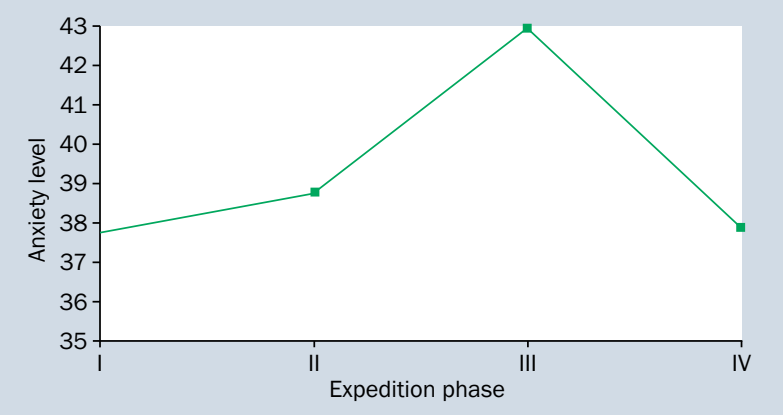

Figure 1. Dynamics of state anxiety in the sample of fishermen $(\mathrm{n}=78)$

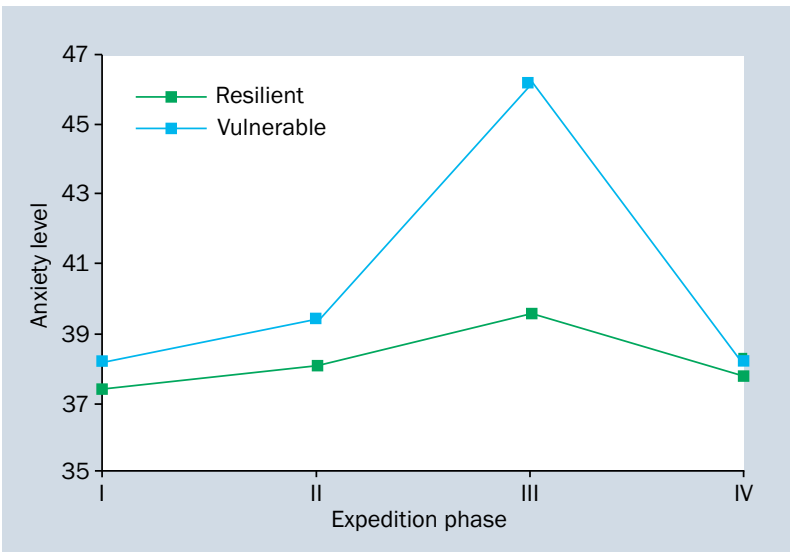

Figure 2. Patterns of anxiety levels among the resilient and vulnerable fishermen
The two distinguished groups differ both with respect to the magnitude of experienced anxiety as well as to the changes in its intensity throughout the expedition. Significant intergroup differences emerged in phase III ( $p>0.001)$. The resilient group $(n=37)$ showed little variability in anxiety - differences between subsequent expedition phases were nonsignificant. In other words, these fishermen exhibited similar levels of anxiety throughout the expedition, neither increasing nor decreasing as isolation continued. On the other hand, the vulnerable group $(n=41)$ experienced a significant increase in anxiety between phases II and III, which nevertheless returned to baseline levels in phase IV, near the end of the expedition. Thus, these fishermen were more susceptible to the deleterious effects of isolation and they experienced increased emotional costs of functioning as it continued.

These two groups were analysed further in order to describe their differences in various demographic variables, such as age, relationship status, sailing experience, position in the crew, education, socioeconomic status of the family of origin, and upbringing in cities/rural areas, as these can contribute, at least partially, to stress resilience/vulnerability.

\section{ANXIETY AND AGE}

The chi-square test revealed significant differences in anxiety levels between three age groups - those below 30 years of age, those aged 31 to 40 years, and those above 41 years $\left(\chi^{2}=8.2, p<0.2\right)$.

Thus, a relationship between the fishermen' age and reported anxiety was revealed in the group aged over 41 years. Compared to younger fishermen, they experienced greater increases in anxiety in the middle phases of the expedition.

Table 3. Anxiety levels throughout the expedition in the two fishermen groups

\begin{tabular}{lllll}
\hline & \multicolumn{2}{l}{ Resilient fishermen $(\mathbf{n}=\mathbf{3 7})$} & \multicolumn{2}{l}{ Vulnerable fishermen $(\mathbf{n}=\mathbf{4 1})$} \\
\hline Expedition phase & $\mathbf{M}$ & $\mathbf{S D}$ & $\mathbf{M}$ & $\mathbf{S D}$ \\
\hline I & 37.38 & 8.72 & 38.13 & 8.02 \\
II & 38.08 & 8.67 & 39.48 & 7.61 \\
III & 39.60 & 8.01 & 46.16 & 8.32 \\
IV & 37.73 & 8.83 & 38.04 & 8.43 \\
\hline Compared phases & $\mathbf{T}$ & $\mathbf{P}$ & $\mathbf{T}$ & $\mathbf{P}$ \\
\hline I-II & 0.34 & NS & 0.77 & NS \\
I-III & 0.78 & NS & 4.39 & 0.01 \\
I-IV & 1.14 & NS & 0.22 & NS \\
II-III & 0.17 & NS & 3.75 & 0.01 \\
II-IV & NS & NS & 0.80 & NS \\
III-IV & 0.15 & & 4.34 & 0.01 \\
NS- non significant; SD - standard & 0.95 & &
\end{tabular}




\section{ANXIETY AND EDUCATION}

The results show that education, separated into four levels (primary school, vocational school, high school, college), is a significant predictor of anxiety vulnerability during long-term isolation $\left(\chi^{2}=14.64, p<0.01\right)$. This relationship mainly concerned individuals with primary school education. Among 18 such fishermen, 22.2\% were in the resilient group, and $77.8 \%$ - in the vulnerable group. An opposite tendency was observed among the fishermen with high school and college-level education.

\section{ANXIETY AND RELATIONSHIP STATUS}

Results revealed that relationship status (single vs. married) did not influence the fishermen' resilience/vulnerability to stress. Similar numbers of single and married fishermen comprised each group.

\section{ANXIETY AND JOB EXPERIENCE}

This relationship did not reach statistical significance, however. Nevertheless, it points to a trend $\chi^{2}=9.29$, $p<0.06)$. The vulnerable group comprised $66.7 \%$ of fishermen on their first deep-sea expedition, $70.6 \%$ of the fishermen with less than 5 years of experience, and only $29.7 \%$ of fishermen with medium amounts of experience (6-15 years).

\section{ANXIETY AND CHILDHOOD PLACE OF RESIDENCE}

Chi-square results for the current study's sample have confirmed such a relationship at a level of statistical trend $\left(\chi^{2}=4.9, p<0.1\right)$.

This relationship/tendency predominantly concerned fishermen raised in large cities. Most of them have been classified to the vulnerable group (70.8\%). This suggests that individuals who have been raised in urban areas might experience greater difficulties in coping with long-term isolation. However, this topic requires additional analyses.

\section{ANXIETY AND CREW POSITION}

In the current sample, $76.5 \%$ of the officers were classified into the resilient group, compared to $39.3 \%$ officers in the vulnerable group. This difference is statistically significant $\left(\chi^{2}=7.23, p<0.001\right)$.

\section{ANXIETY LEVELS AND JOB SATISFACTION}

The results confirm the relationship between job satisfaction and levels of experienced anxiety during deepsea expeditions. The majority (67.6\%) of fishermen classified into the resilient group reported high job satisfaction $\left(\chi^{2}=9.84, p<0.01\right)$. Thus, it can be inferred that motivated individuals, who do not treat their work instrumentally (i.e., as a means to an end) are able to cope more effectively with its demands, as evident by no significant increases in their reported anxiety throughout the expedition.

\section{SUMMARY AND DISCUSSION}

Long-term exposure to stress can be viewed through the lens of personal costs. One of its basic measures is state anxiety. State anxiety is the subjective, consciously perceived feeling of worry and tension, with the accompanying activation of the autonomic nervous system [12, 13]. From a cognitive perspective, anxiety is the discrepancy between desired and de facto experienced internal states. The perception of this discrepancy can, in turn, be influenced by subjective and/or objective factors. Objective (situational) factors contribute to anxiety in individuals exhibiting state (behavioural) anxiety, comprised of blob: https://jsa.opi. org.pl/084716a8-0520-45dc-a7db-1ba6fd23022b subjectively felt tension and increased activity of the autonomic nervous system $[13,14]$. The subjective factors in anxiety involve various emotional deficits stemming both from isolation itself as well as unrealistic expectations. Anxiety can be a reaction to sparse social and emotional relationships or a sense of danger, not necessarily caused by the presence of actual physical threats. Anxiety is an internal state that is difficult to describe in terms of singular and specific cognitive processes, emotions, or behaviours [15, 16].

In line with the interactional model of stress, it can be assumed that stress levels and its dynamics vary as a function of demographic and social factors. Differences in such "profiles" of stress reactions can be expected to depend on individual vulnerability or resistance to stress - some individuals will show a negative (increasing stress) dynamic, while others - a positive one (no increase or lowering stress). These dynamics will be compared between the experimental groups distinguished in the current study through cluster analysis, taking into account specific demographic variables

The results can be summarised as follows:

1. Measuring the fishermen' state anxiety in four phases of the expedition $\left(10^{\text {th }}, 60^{\text {th }}, 100^{\text {th }}, 130^{\text {th }}\right.$ day) showed a varied dynamic. Anxiety increased from the beginning, reaching its highest levels in phase III, after which it returned to the initial levels. This confirms the hypotheses put forward by other researchers about the existence of a specific isolation syndrome, emerging in the midpoint of the isolation period and involving lowered cognitive performance, increased interpersonal contacts, psychosomatic symptoms, irritability, and emotional dysregulation.

2. Cluster analysis has distinguished two groups of fishermen with respect to their psychological resilience. The resilient group showed near-constant, low levels of anxiety throughout the expedition. In contrast, the vulnerable group experienced a steady increase in anxiety up to phase III (the $100^{\text {th }}$ day) of the expedition, after which it returned to its initial levels. Telerak [see 17] showed that the greatest psychological costs during a 14-month 
polar expedition were incurred in the initial phase. Studies also suggest that the appraisal of isolation is related to emotion regulation abilities. The current study points to the necessity of adopting an individual differences perspective when studying such groups.

3. A relationship between the fishermen' age and their stress resilience/vulnerability was revealed. Fishermen over 40 years of age were more susceptible to stress than their younger colleagues. This can be related to a decreasing tolerance for environmental difficulties, which would facilitate quicker physical and mental exhaustion. In turn, separation from social support networks can be the most significant difficulty for the younger fishermen $[4,5]$. Presumably, this is due to greater exposure to and a subsequent lower tolerance to the demands of isolation at sea. Greater susceptibility to anxiety can be related to quicker physical and mental exhaustion, which becomes the most evident during the most difficult expedition phase.

4. Fishermen with primary school-level education and fishermen who were on their first deep-sea expedition generally experienced greater anxiety. In contrast, officers and fishermen reporting high job satisfaction were more resilient to stress. Individuals with lower education levels likely have greater difficulties in adapting to ship conditions. They occupy lower positions in the crew, are assigned lower quality living quarters, and experience lower job satisfaction.

5. Education could also reflect career aspirations, and thus can be indirectly related to a low need for self-realisation. Fishermen with lower education levels report mainly being motivated by financial concerns. In the current study, these fishermen were also observed to abuse alcohol the most frequently, possibly as a maladaptive way of regulating the anxiety of long-term isolation. Fishermen with higher education, mostly holding officer ranks, exhibited a greater motivation and experienced lower anxiety during the most challenging phases of isolation. They presumably chose their position consciously and deliberately. Responsibility for expedition could also have mediated their stress resilience.

6. Fishermen with low job experience or participating in a deep-sea expedition for the first time also showed increased susceptibility to anxiety. The initial period of a career as a sailor thus seems to be related to increased emotional costs. These could be related to difficulties in anticipating challenging situations, the novelty of the experience, and difficulties in separating from the usual dynamics of life on land. Job experience as a fisherman denotes the acquired skill and task proficiency as well as the accumulation of specific physical and mental consequences of repeated long-term isola- tion in difficult conditions. Thus, it can be expected to influence stress vulnerability. These data might suggest that fishermen who have gathered appropriate experience and developed effective coping mechanisms, but have not yet begun experiencing burnout-like symptoms are the most resilient. In turn, risk factors of vulnerability might include difficulties in anticipating various challenges, novelty of the expedition conditions, and negative emotions related to separation from family and from land.

7. Those fishermen who grew up in large cities displayed lower resilience to stress on a level of statistical tendency. This effect requires further study, though it seems to suggest that growing up in urban environments facilitates a greater need for stimulation. Place of residence in childhood might influence the need for stimulation later in life. For example, it can be expected that people who spent their childhood/adolescence in rural areas might cope better with the monotony of a sailing expedition in contrast to people who were raised in urban areas which shape a greater need for stimulation.

8. Fishermen satisfied with their job and seeing it as valuable in itself are more resilient to anxiety. Work on a fishing vessel requires specific personal predispositions. Thus, it can be assumed that individuals who find difficult work in difficult conditions personally appealing will be more resilient to stress experienced during that work.

These results suggest that the dynamics of anxiety experience in conditions of long-term isolation has varied underlying causes and that psychological functioning in especially difficult environments is generally related to individual life experience, constructed and reconstructed in various developmental periods and social contexts. Such variables as age, education, and job experience determine the life experience of a sailor on a deep-sea expedition. However, a wide range of other individual and social factors must additionally be considered. Attempts at such research are presented in Plopa [17-19].

Coping with the stress of isolation during the initial phases of the expedition was similar for the entire studied sample, with differences emerging only in the subsequent phases. Some sailors experienced stable levels of anxiety, while others reported an increase. The results confirmed the hypothesis, suggested in earlier research, that the middle phase of the expedition is the most demanding psychologically.

The value of the current study thus lies in identifying areas of further research on factors determining stress resilience. Adaptive functioning in short-term situations, even of intense stress, most likely relies on other psychological resources (e.g., decision-making) than does functioning in 
prolonged conditions of stress where, for example, factors related to personality and social support networks come into greater prominence. For these reasons, the value of laboratory experiments for predicting individual functioning during long-term isolation is limited. On the other hand, the current research was carried out in highly difficult conditions of long-term deprivation and involved almost an entire crew of a fishing vessel. Prior research on natural isolation has usually involved much smaller samples, which limited the ability to consider individual differences. Also importantly, the current study addressed the personal psychological costs incurred by the sailors during the expedition rather than their job/task effectiveness, as was the case in much of the prior research.

The current study was based upon the transactional conception of stress, in which stress is the result of an interaction between an individual and their environment. This allowed for greater emphasis on the psychological underpinnings of this interaction as a whole. For example, an individual can subjectively perceive their objectively difficult conditions as relatively non-threatening, but can nevertheless experience stress on a physiological, psychological, or interpersonal level. The results of the current study have shown that an individual's perception of their current condition can be determined by their life experience (i.e., demographic variables). Thus, for some, this perception will be realistic and adaptive for some, and more biased and maladaptive for others. In conditions of long-term isolation, the influence of life experience, and, consequently, the experience of stress, will vary over time.

\section{REFERENCES}

1. Hystad S, Bye H. Safety behaviours at sea: The role of personal values and personality hardiness. Safety Science. 2013; 57: 19-26, doi: 10.1016/j.ssci.2013.01.018.

2. Leszczyńska I, Jeżewska M. Psychosocial burden among offshore drilling platform employees. Int Marit Health. 2010; 62(3): 159-167, indexed in Pubmed: 21154303.

3. Johnsen BH, Meeùs P, Meling J, et al. Cultural differences in emotional intelligence among top officers on board merchant ships. Int Marit Health. 2012; 63(2): 90-95, indexed in Pubmed: 22972548.
4. Peplińska A, Jeżewska M, Leszczyńska I, et al. Stress and the level of perceived anxiety among mariners: the mediating role of marital satisfaction. Int Marit Health. 2013; 64(4): 221-225, doi: 10.5603/ imh.2013.0008, indexed in Pubmed: 24408144.

5. Peplińska A, Rostowska T. Quality of life and relations between work and family. Acta Neuropsychologica. 2013; 11: 77-92.

6. Carotenuto A. Psychological stress in seafarers. Int Marit Health. 2012; 63: 188-194.

7. Håvold J. Stress on the bridge of offshore vessels: Examples from the North Sea. Safety Science. 2015; 71: 160-166, doi: 10.1016/j. ssci.2014.03.009.

8. van Leeuwen WMA, Kircher A, Dahlgren A, et al. Sleep, sleepiness, and neurobehavioral performance while on watch in a simulated 4 hours on/8 hours off maritime watch system. Chronobiol Int. 2013; 30(9): 1108-1115, doi: 10.3109/07420528.2013.800874, indexed in Pubmed: 23879695.

9. Hjarnoe L, Leppin A. A risky occupation? (Un)healthy lifestyle behaviors among Danish seafarers. Health Promot Int. 2014; 29(4): $720-$ 729, doi: 10.1093/heapro/dat024, indexed in Pubmed: 23630132.

10. Roberts SE, Jaremin B, Chalasani $P$, et al. Suicides amongseafarers in UK merchant shipping, 1919-2005. Occup Med (Lond). 2010;60(1):54-61, doi: 10.1093/occmed/kqp133, indexed in Pubmed: 19805397.

11. Chauvin C. Human factors and maritime safety. J Navigation. 2011; 64(4): 625-632, doi: 10.1017/s0373463311000142.

12. Wrześniewski K, Sosnowski T, Jaworowska A, Fecenec D. Inwentarz stanu i cechy lęku. Polska adaptacja STAI [State-Trait Anxiety Inventory. Polish adaptation of the STAI]. Pracownia Testów Psychologicznych PTP; Warsaw, Poland, 2011.

13. Spielberger CD. Theory and research on anxiety. In Spielberger CD (ed.) Anxiety and behavior. Academic Press, New York 1966: 3-20.

14. Spielberger CD. Anxiety: State-trait-process. In: Spielberger CD and Sarason IC (eds) Stress and anxiety. Vol. 1. Wiley, Washington, DC 1975: 115-143.

15. Tzannatos E, Kokotos D. Analysis of accidents in Greek shipping during the pre- and post-ISM period. Marine Policy. 2009; 33(4): 679-684, doi: 10.1016/j.marpol.2009.01.006.

16. Bergin AJ, Jimmieson NL. The importance of supervisor emotion recognition for praise and recognition for employees with psychological strain. Anxiety Stress Coping. 2020; 33(2): 148-164, doi: 10.1080/10615806.2020.1716975, indexed in Pubmed: 31965831.

17. Plopa M. Anxiety dynamics in sea isolation: Family determinants. Pol J Social Science. 2007; 2(1): 99-119.

18. Plopa M. Psychological studies of stress experienced by seamen during a long-distance sea voyage. Pol J Social Science. 2015; 10(1): 247-259.

19. Plopa M, Makarowski R, Piotrowski A. The human factor in maritime transport: personality and aggression levels of master mariners and navigation students. Advances in Cognitive Psychology. 2020; 4. 